laryngitis is no other than the laryngeal affection described as asthma by Millar and Wichmann; stridulous angina by Bretonneau; false croup and stridulous laryngitis by Guersant. Bretonneau considered it to consist of a catarrhal condition, and Guersant of a slight inflammation of the laryngeal mucous membrane. They, however, define it to be a complex condition in which is developed under the influence of catarrh a congestion or a laryngeal phlegmasia, associated with a spasmodic contraction of the muscles of the larynx.

In the second place, in vol. ii, p. 498, in the class of neuroses, they describe under the head of "convulsion interne (spasme de la glotte)" a disease which, they say, is known under the names of thymic asthma, Kopp's asthma, spasm of the glottis, laryngismus stridulus, etc.; and, when discussing the question of diagnosis, they arrange in a tabular form the distinctive features of "laryngite spasmodique" and "spasme de la glotte".

It is evident, therefore, that, by the terms false croup and stridulous laryngitis is implied an inflammatory condition, which Rilliet and Barthez, however, admit is always slight ("mais toujours légère"), and which, they say, many medical men have confounded, even of late years, with laryngismus stridulus.

\section{THE CASE OF ARTHUR O'CONNOR.}

By HARRINGTON TUKE, M.D., F.R.C.P.

THE case of Arthur O'Connor is a striking instance of the mistaken views frequently adopted by lawyers as to the value of medical evidence in cases of insanity, and also is an exceptionally strong example of the way in which an advocate, aiming at success, will do his utmost to discredit a medical witness, even although he feels the force of the facts upon which the expert has founded his opinion.

In April 1872, Arthur was arraigned for treason-felony. $\mathrm{He}$ had pleaded guilty before the Grand Jury; it is quite clear that he did so under a misapprehension. After some demur on the part of the Court, this plea was allowed to be withdrawn, and the trial proceeded.

The case rested almost entirely upon medical evidence. This was to the effect, that Arthur O'Connor had long been in ill health; his head had received a severe injury; since that time his disposition had changed. There was a strong hereditary predisposition to insanity : had had a sudden idea to shoot the Queen, but had abandoned that course for one of intimidation. $\mathrm{He}$ had intended to attack $\mathrm{Her}$ Majesty in St. Paul's Cathedral on the Day of Thanksgiving for the recovery of the Prince of Wales. Turned out of the cathedral at two in the morning, he had returned at eight; the crowd prevented his reaching it again, or getting near the Royal carriage. Persistently tracking the Queen, he at last got near her Majesty's person, climbing the iron railings of Buckingham Palace; he had time to present a pistol at the Queen's head before her attendants could arrest him. Upon him was found a coherent but insane document, purporting to be a pardon for the Fenian prisoners, and an order for O'Connor's own execution. Other insane documents were produced. These the counsel for the prosecution objected to receive.

I had seen the boy, at the request of his father, about three weeks previously, and found him to be clearly of unsound mind, entertaining insane opinions, that rendered him dangerous to others. In this view of the case I was strongly confirmed by Dr. Maudsley, who examined the boy with me, and also by Dr. Sabben, who saw him afterwards.

The paroxysm of insanity that led to his outrage seems to have lasted about six weeks, leaving him in his normal state of hypochondriasis and almost imbecility, with a tendency to recurrent attacks, in which he becomes dangerous. The subsequent history of his case entirely corroborates this diagnosis. While in Australia, this condition of insane hypochondriasis continued; and as to the state of his mind, it may be enough to mention that though at times fairly well, at others he had paroxysms of absolute mania. Among other eccentricities, he wrote letters to Her Majesty, one of which suggested that he should be made Poet Laureate in succession to Tennyson. On the occasion of the last Drawing-room, O'Connor was found in an excited condition, waiting, it is supposed, for Her Majesty, near the very same place at Buckingham Palace in which his former mad assault upon her was committed.

One of the Queen's physicians, and subsequently Dr. Tweedie, saw O'Connor with me before his arrest. The following is his own written account of his symptoms :

"Physical Symptoms. Back like ice ; want of ability to swallow food. Sinking in Stomach. In cold weather one moment-deadly cold, the next burning hot-pains in the head-completely stupified by cold weather - Mental - want of rest-thought continually re- volving upon religion. Visions at night of angels hurling men down precipices to die for ever because they had not given up all they loved and go and sell Bibles to the unconverted. Sense that unless I gave up the drama, witty and convivial Society, novel writing, and the world completely I should be everlastingly damned. In a word, one unceasing mania concerning Jesus Christ-the intellect warring with extreme views yet unable to crush the ever revolving mania. Sense of utter want of constitution and energy in comparison to what I ought to be.

"Naturally I am a poet loving the dramatic writers and poet of nature and at one time of my life, ere I become physically debilitated, quite unsusceptible to the present mania, which leaves me no rest day nor night. Of late my brain agony has terribly increased I awoke the other night raging to commit suicide; the idea occurred as a very delightful one, and just as I was about to spring from my bed to act upon it -it passed off and left me trembling all over and utterly horrified.

"Since then my feelings have risen to absolute madness continually and I know very well it is all physical desease, a dead liver or something of the kind. My home is very wretched, it is in fact a hell to me.

"Naturally I am devoured by energy, running in my walk, and in everything else, but when stupified by dyspepsia scarcely able to drag a foot."

The apparently unanswerable evidence of the insanity of O'Connor at the time of his outrage upon the Queen, was demolished by the Attorney-General in his cross-examination, mildly described in the Times as occasionally "caustic". This was done with great, but, it must now be admitted, with misapplied forensic ability ; and, without hearing a single witness for the Crown, the jury stopped the case, and found that the prisoner was, and had always been, of sound mind. This, perhaps, also stopped the Attorney-General's speech-fortunately, perhaps, as I was his first subject since he had showered vituperation upon the Tichborne Claimant. The ultimate result of this trial should lead future counsel to pause before they utterly ignore experienced medical testimony, at all events, in the prosecution of cases of treason-felony. They may succeed in gaining a verdict, and for the moment overwhelming the physician with ridicule. But supposing, as time has proved in this case, they are in the wrong, hard labour and stripes, and a short imprisonment as a felon, are not likely to cure insanity; and the course taken by the AttorneyGeneral might have imperilled the safety of the Sovereign. As it is, it has nearly led to her being seriously alarmed by the reappearance of the deranged and wild-looking young man near the royal carriage, in the same place where he had before eluded the watchfulness of her attendants.

Another result of the Attorney-General's "unfortunate" advocacy (I have to thank him for applying to my evidence and so "teaching me that word"') has been that three years have been lost; Arthur O'Connor is at last committed to Hanwell Asylum. Under gentle care and treatment in his first attack, he might have recovered. He may do so now ; but his chances are materially lessened.

The characteristic judgment and clemency of Her Majesty led to the remission of the hard labour and whipping to which O'Connor had been sentenced, and also to a shortening of the term of his imprisonment. If this had not been so, a curious incident would have illustrated the mistake of the law advisers of the Crown : some of the Fenian sympathisers seriously proposed to $\mathrm{Mr}$. O'Connor that a procession should be formed to meet his son on his release, and to escort him with due honour to his father's home. It should be quite understood that Mr. O'Connor was entirely opposed to this absurd proposal. I have never noticed the caustic examination of the Attorney-General; nor shall I now, except upon one point-the one by which the jury, and indeed a large section of the public, were mainly misled. It is deserving of careful attention, because it constantly arises in criminal trials, and was in this of paramount importance.

The Attorney-General contrived to persuade the jury that, if they acted upon the medical evidence, the prisoner would be confined for life in Broadmoor Asylum as a criminal lunatic; whereas, if they took the legal view of the case, he would escape with a comparatively trivial and salutary punishment. Now, this was trebly "unfortunate". It was purely an ad captandum argument, and entirely irrelevant to the question of the truth of the evidence, which ought not to be, and was not, in any way biased by co.ssideration of results. It, moreover, offered a temptation to the jury to do the wrong, that right might come of it. I was unfairly taunted with attempting to injure, while I was professing to assist. Now, stripped of forensic tinsel, the plain truth stands thus : the parents of the boy, who was then only 17 years of age, were convinced of his insanity, alarmed at his evidently dangerous condition, and most anxious to have for him any treatment that might permanently cure him; they were respectable people, who had been in a superior position, and 
they were averse to their son's being branded as a felon; it was, therefore, afier anxious consultation with them and their counsel, that the course inveighed against by the Attorney-General was adopted; and, in the event of Arthur O'Connor's recovery at Broadmoor, his parents trusted to the strong evidence of the son's previous good character, and thoroughly relied upon his being the subject of the never failing clemency of Her Majesty.

I freely forgive Lord Coleridge for his personal attack upon myself ; it was possibly his professional duty to break down, by every possible means, a witness hostile to his own views ; but he must surely now deeply deplore his share in a proceeding which consigned a sick and insane boy to degrading punishment, and to a prison instead of a hospital, thus, perhaps, rendering him a hopeless lunatic; he may also regret that he treated a medical witness with much discourtesy, anci ridiculed scientific evidence that has ultimately proved correct; and he must feel deeply that his unfortunate advocacy very nearly resulted in injury or alarm to the Royal Mistress whom it was his special duty to protect and defend.

I trust the case of Arthur O'Connor may either lead the English Bar to more extended study, or induce them to receive with greater attention and respect the evidence of those who make medical and other scientific investigations the pleasure and business of their lives.

\section{OBSTETRIC MEMORANDA.}

\section{ERYSIPELAS AND PUERPERAL FEVER.}

IN Mr. T. Spencer Wells's address on puerperal fever, published in the JOURNAL on April I 7 th, I find the following. " A country surgeon attends a man who has erysipelas after a broken arm. He also attends a healthy woman in an isolated cottage in a natural labour. There is no puerperal fever in the district, yet this woman dies of puerperal fever. . . . Such a history as this would have tenfold weight, as being free from numerous sources of fallacy and doubt."

On the night of February I Ith last, my assistant went to attend a man who had fallen down and cut his head open over the occiput down to the bone. The wound was about an inch long. On the second night, it bled, evidently from a small artery, which he arrested by a compress of lint. On the 2oth, the man was taken very ill. I myself went to see him, and found that he had been suffering from rigors. I examined the wound; the scalp was somewhat swollen. I carefully washed and dressed the part. The same evening, I was called to attend a woman in confinement (age about 37 , fifth child), who had a natural labour. The next day $I$ found that the man was suffering from erysipelas; it was running down over the forehead. On the 22nd, the woman had a chill, with all the symptoms of puerperal fever setting in. She died on the 27th; the man likewise died on March Ist. I took every precaution whilst attending other cases, and did not wear the same external clothing; so I did not infect any other lyingin woman. Early on March 3rd, I attended another woman (age 22, second confinement) who, on the day following, had all the symptoms of the previous case. I questioned the nurse, as she came from the village where the man died, whether she had been in the house. She informed me she had been there to assist, and left that place direct to go to the woman in labour. That case terminated fatally on the roth. The child had erysipelas at the navel, which spread all over the body; it died on the 18 th. A nurse, who was in almost constant attendance upon the man, had an abrasion on the nose; she had erysipelas on March 3 rd, and died on the 7 th. Whilst attending the man, I was also daily dressing two women, each for an ulcerated leg; both had erysipelatous inflammation of the leg. The husband of one, an old man, aged about 78 , had erysipelas over the head and face, from which he got better, but died of exhaustion on May 6th. A son of the old man's master called to see him on April 25th; he had a slight scratch on the septum of the nose. On the 27 th, erysipelas made its appearance, and spread over the face, from which he has now recovered.

To go back again to the first case. On March I3th, a woman, who had been several times to see the man (whose house was directly opposite her own) had a severe attack of erysipelas over the head and face; she recovered. A young woman likewise visited her, and at the same time had her ears pierced for rings ; erysipelas affected them, and spread rapidly over the head and face; she recovered after a severe attack. During the interval of the two puerperal cases, I attended other women, who escaped infection. Thus, I had nine cases of erysipelas and two of puerperal fever, with six deaths, all to be traced from the first. In looking over my midwifery list, I find I had previously attended I, I 39 cases without losing one. I have been in practice twenty-five years, and, during that time, I have only lost four cases, not including the last two I have previously mentioned. One died of inflammation of the lungs, three days after confinement ; another (a turning case) of peritoneal inflammation, three weeks after confinement; another of scarlet fever; and the fourth of puerperal fever, the cause of which I could not discover. I generally make it my practice, if I have any contagious disease about, to visit my childbed cases first; the doing so, I think, is one reasons why my death-rate is so low. Idiopathic erysipelas I consider not contagious; but traumatic, being caused by pyæmia, I think is, and $I$ hold that it would be very unwise to attend a labour directly after visiting such a case. I have had many cases of the former kind, but cannot now remember ever losing one, nor have I seen that another person has taken it from one so affected.

$$
\text { S. N. Squire, M.R.C.S. and L.S.A., Wivenhoe. }
$$

\section{PUERPERAL FEVER AND SCARLATINA.}

IN reference to a remark of Dr. Braxton Hicks in the discussion on puerperal fever, I may say that I have seen three cases of well-marked scarlatina coming on within a day or two after delivery. Two of these were unfortunately fatal in a short time. At the same time, I have not unfrequently seen lying-in women exposed to the contagion of scarlatina without any ill effect. The two fatal cases seemed to die from the fever alone, without any special uterine or pyæmic symptoms.

J. Walters, M.B., Reigate.

\section{CLINICAL MEMORANDA.}

\section{CROUP AND DIPHTHERIA.}

I sHOULD like to say a few worls, partly by way of explanation and correction of the hurred communication in the JOURNAL of last week. Acute affections of the larynx I should divide into-I. Laryngismus stridulus; 2. Simple laryngitis, including $(a)$ catarrhal, $(b)$ herpetic, (c) membranous; 3. Specific laryngitis, including $(a)$ diphtheritic, $(b)$ syphilitic, (c) scrofulous.

In this arrangement, the difficulty of diagnosis will lie between herpetic and membranous laryngitis and diphtheritic disease. In this, we must be guided by the presence or absence of any epidemic of diphtheria, and by the presence or absence of any throat-affection, as also by the general constitutional symptoms which, in the malignant type of diphtheria, will be sufficiently well marked to enable us to come to a decided opinion as to the nature of the disease. But the difficulty will be greatest where no accurate history can be obtained as to the prevalence or not of diphtheria, and as to whether, in the case of the patient, the throat has been affected, or has been free. In these circumstances, it may be impossible to arrive at an accurate conclusion during life; and after death, if such be the result, I doubt much whether, in the present state of our knowledge, we would be able even then to decide. Dr. Cumming says the two kinds of membrane are quite distinct in their gross characters, and I do not doubt them to be so in comparing the extremes. But I think most observers will allow that, even in genuine diphtheria, membranes of an elastic white description are frequently produced. Should, however, Dr. Klein's investigations into the nature of typhoid fever lead to establishing the fact of the presence of vegetable organisms as a constant phenomenon peculiai to that disease, then I think we may confidently look forward to the time when similar discoveries will be made in diphtheria, and then we will be able perhaps during life to say with certainty that a case is simple or specific in its nature.

Though the treatment of laryngitis is not under discussion, I should like to add that, in my experience in rural districts, simple laryngitis, when seen early and treated boldly, is a very curable disease. With regard to diphtheritic laryngitis, where there are decided signs of constitutional disease, I think it prudent not to meddle by surgical interference, unless, indeed, as in such cases as the lamentable one of last week, the operation be resorted to with the idea of prolonging life rather than with the hope of saving it. But, in the milder slower cases, whether of diphtheritic disease or of herpetic affection of the larynx, tracheotomy, when early performed, will save many lives. Within the last four years, out of six cases, I have had three recoveries, and this, too, where undoubtedly the operative means were too long delayed. I attach great importance to the slow progress of the disease as a hopeful sign. In rapid or acute cases, the mischief done to the lungs by enforced stasis of the circulation and emphysema of the aircells, though the relief seems decided for a time, is only apparent, and the fell result is only postponed, not prevented.

William BRUCE, M.D., Dingwall, N.B. 